\title{
Research Paper: Effectiveness of Mental Immunization Program Training on Social Competency and Personality Traits of Individuals With Cerebral Palsy
}

\author{
*Mohammad Ashoori ${ }^{1}$, Masoume Pourmohamadreza-Tajrishi ${ }^{2}$, Seyyedeh Somayyeh Jalil-Abkenar ${ }^{1}$, Ali Mohammad Fallah' ${ }^{1}$, \\ Samad Azimi Garoosi ${ }^{1}$
}

1. Department of of Psychology and Exceptional Children Education, Faculty of Psychology and Education, University of Tehran, Tehran, Iran.

2. Pediatric Neurorehabilitation Research Center, University of Social Welfare \& Rehabilitation Sciences, Tehran, Iran.

\begin{tabular}{|c|c|}
\hline $\begin{array}{l}\text { Use vour device toscan } \\
\text { and read the artice online }\end{array}$ & Ation: Ashoori M, Pourmohamadreza-Tairishi M, Jalil-Abkenar SS, Fallah AM, Azimi Garoosi S. [Effectiveness of Mental \\
\hline 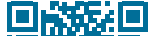 & Immunization Program Training on Social Competency and Personality Traits of Individuals With Cerebral Palsy (Persian)]. \\
\hline 2ating & Archives of Rehabilitation. 2017; 18(2):98-109. http://dx.doi.org/10.21859/jrehab-180296 \\
\hline 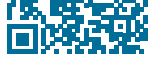 & doi": http://dx.doi.org/10.21859/jrehab-180296 \\
\hline
\end{tabular}

Received: 05 Nov. 2016 Accepted: 27 Mar. 2017

Keywords:

Mental immuniza-

tion, Social competency, Personality traits, Cerebral palsy

\section{A B STRACT}

Objective Most children and adults with cerebral palsy do not have appropriate social competency and personality traits, which in turn leads to psychological problems in their life and negatively affects their interactions. The purpose of the present research was to investigate the effectiveness of mental immunization program training on social competency and personality traits of individuals with cerebral palsy in Tehran city. Materials \& Methods The present research had a semi-experimental study with pretest and posttest design and control group. The study population included adolescents with cerebral palsy in the age group of 12 16 years in the academic year 2015-2016. Subjects were selected with the help of the convenient sampling method. In this study, 34 adolescents with cerebral palsy participated. They belonged to the middle socioeconomical class. The subjects were randomly divided into experimental and control group, each of which consisted of 17 adolescents. The experimental group received psychological immunization program training across 10 sessions (45 minutes for per session; twice a week) while control group did not receive any training. The instruments of present research were social competency questionnaire of Felner, Lease and Philips and big five factor personality inventory (NEO-FFI) of Costa and McCrae. The obtained data were analyzed by using mean, standard deviation and multivariate analysis of covariance (MANCOVA) test with the 21st version of the statistical package for social sciences (SPSS).

Results The normality of variables and contingency of variance and covariance assumptions were tested. The Kolmogorov Smirnov test showed that all variables were normal $(P>0.05)$. The Box test confirmed contingency of variance-covariance assumption $(\mathrm{P}=0.28)$. Therefore, assumptions of MANCOVA test were confirmed and were used the MANCOVA test for analysis of data. The findings of this research showed that there was a significant increase in social competency mean scores of experimental group post intervention in comparison with control group $(\mathrm{P}<0.001)$. Also, personality traits mean scores of experimental group was significantly in neuroticism, extroversion, agreeableness and conscientiousness subscales $(P<0.05)$. In other words, mental immunization program training had a significant effect on these subscales but not on openness $(P>0.05)$ Conclusion The results of the present research indicated a significant increase in social competency in adolescents with cerebral palsy. Also, desirable changes were found to be developed in the personality traits of these adolescents. In other words, there was a decreased level of neuroticism and significant increase in positive traits such as extroversion, agreeableness and conscientiousness. The overall results of the present research indicated that mental immunization program training led to improvement in social competency and personality traits of individuals with cerebral palsy. Therefore, paying attention to the mental immunization program training is essential, and planning for providing of psychological immunization program training is of particular importance. Cerebral palsy affects all aspect of an individual's life and implementing the mental immunization program training has been associated with effective outcomes. Therefore, instructional interventions such as mental immunization program training are required. While a lot of research works have been conducted with regard to the effectiveness of mental immunization program training on social competency and personality traits of normal students, only a few investigations have been carried out for the same in relation to individuals with cerebral palsy. As far as present study used experimental method, could be cautioned in generalization of results. Another limitation of this study is the use of self-reporting questionnaires, wherein individuals do not feel the responsibility to answer correctly and honestly in order to avoid stigma or rejection by the community. It is recommended that the psychological immunization program training, which is very helpful in the instruction of teenagers with cerebral palsy, be used in primary schools and among various categories of exceptional students.

\section{* Corresponding Author: \\ Mohammad Ashoori, PhD}

Address: Department of of Psychology and Exceptional Children Education, Faculty of Psychology and Education, University of Tehran, Tehran, Iran Tel: +98 (21) 36728780

E-Mail: ashorihh2@gmail.com 


\title{
اثربخشى برنامه ايمنسازى روانى بر كفايت اجتماعى و صفات شخصيت افراد با فلج مغزى
}

\author{
"محمد عاشورى'، معصومه يورمحمدرضاى تجريشى'، سيدهميه جليل آبكنار'، علىمحمد فلاح'، صمد عظيمى كروسى'
}

ا- كروه روانشناسى وآموزش كودكان استئنايى، دانشكده روانشناسى و علوم تربيتى، دانشكاه تهران، تهران، ايران.

r- إمركز تحقيقات توانبخشى اعصاب اطفال، دانشكاه علوم بهزيستى و توانبخشى تهران، ايران.

\begin{abstract}
حكيد

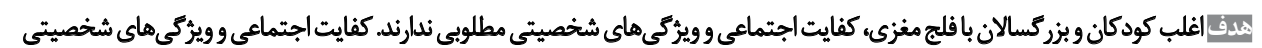

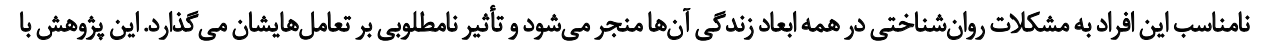

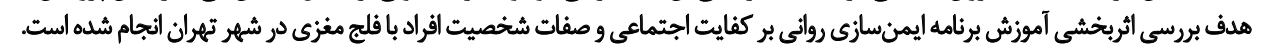

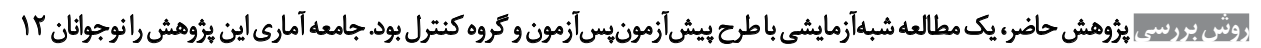

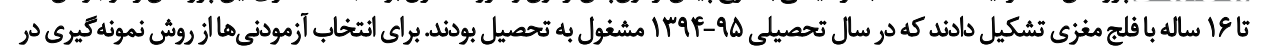

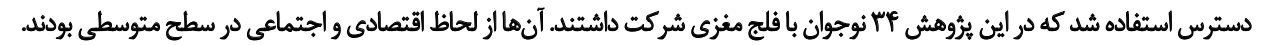

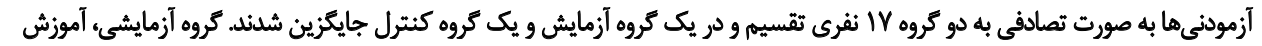

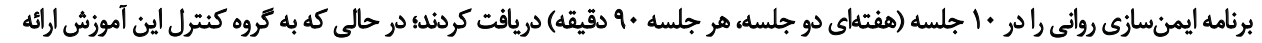

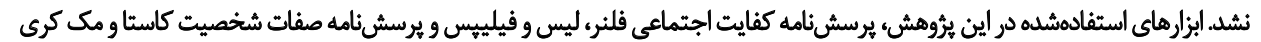

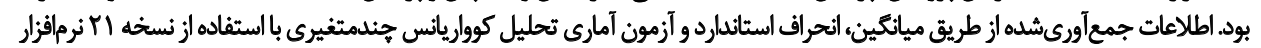

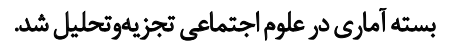

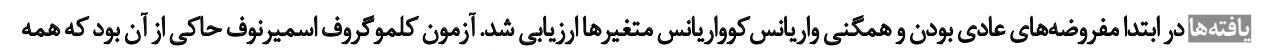

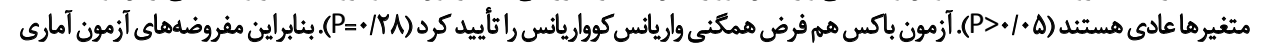

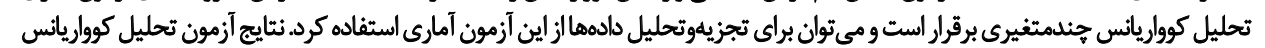

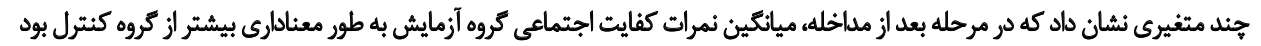

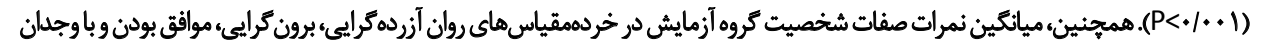

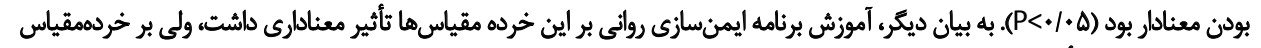

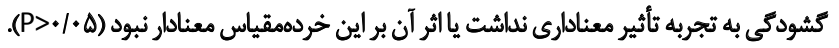

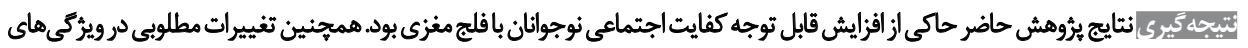

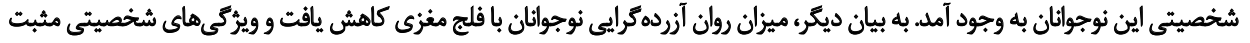

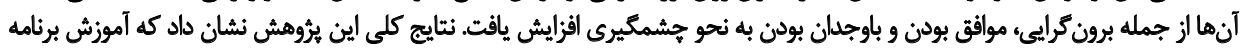

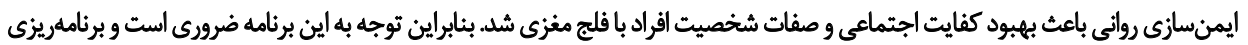

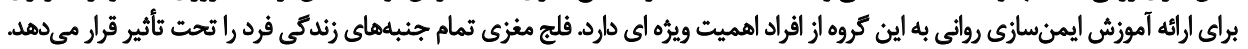

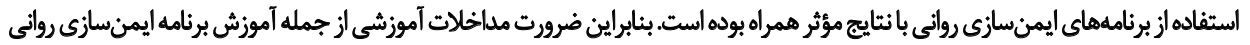

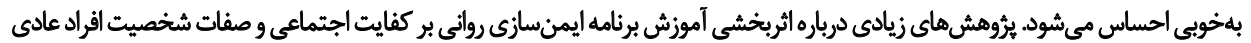

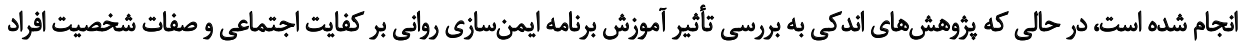

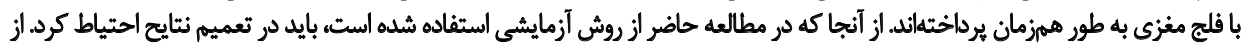

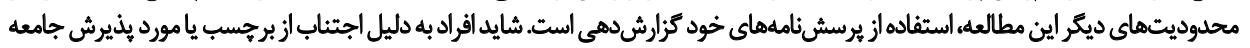

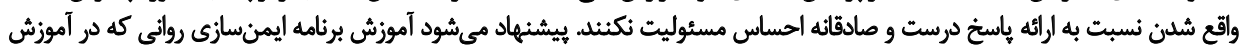

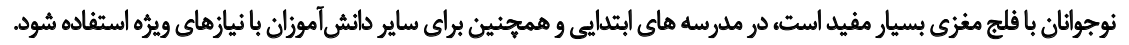

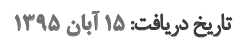

تاريخ يذيرش: Vاثروردين

كليدواروها:

ايمنسازى روائى،

كفايت اجتماعي، صفات شخصيت، فلج مغزى

두.

$$
\begin{aligned}
& \text { : نويسينده مسئئول: } \\
& \text { دكتر محمد عاشورى }
\end{aligned}
$$

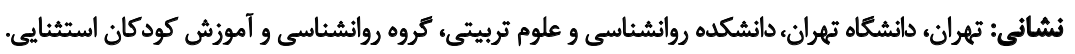

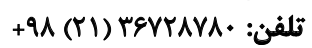

$$
\begin{aligned}
& \text { رايانامه: ashorihh2@gmail.com }
\end{aligned}
$$




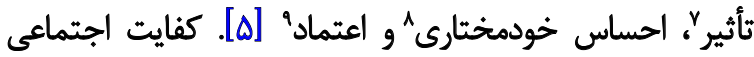
مقلمه

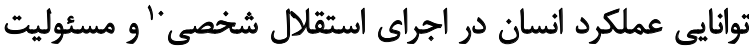

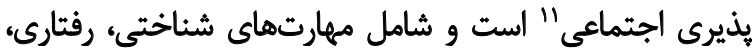

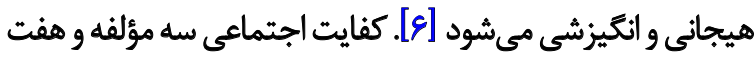

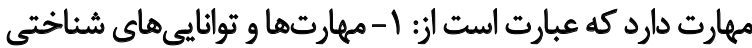

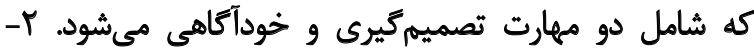

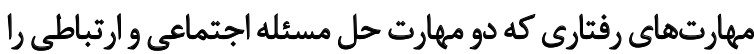

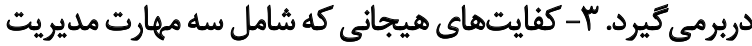

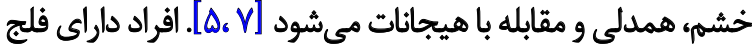

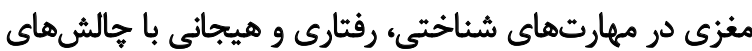

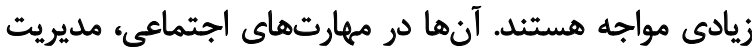
روابط، كنترل هيجانات مشكل دارئد [ب]

بيشتر افراد با فلج مغزى زودرنج و درونكرا هستند و ويثُكى هاى

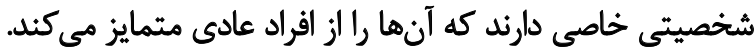

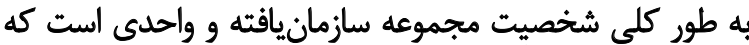

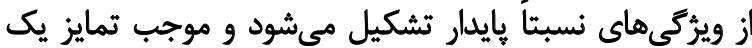

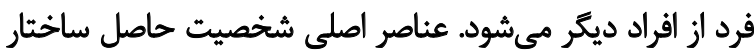

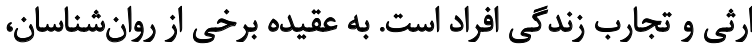

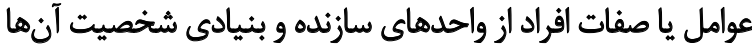

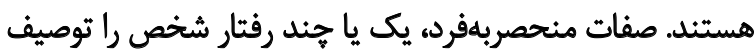

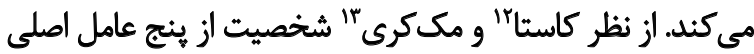

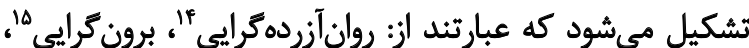

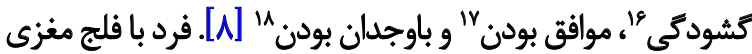

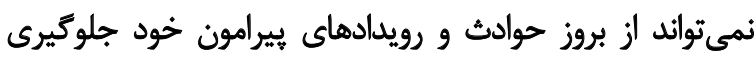

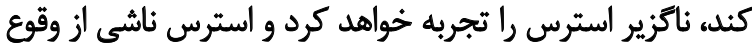

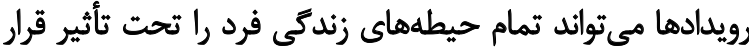

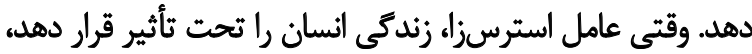

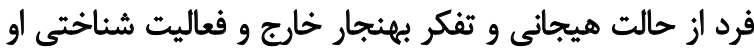

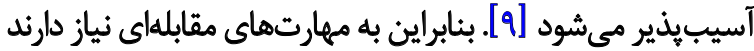

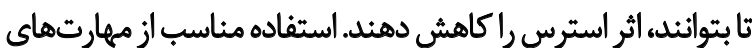

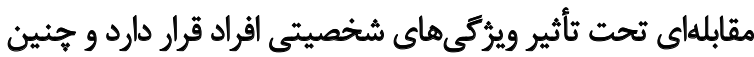

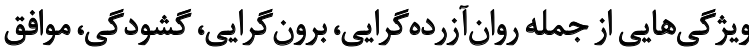

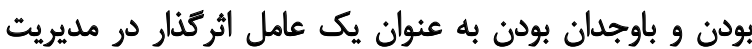

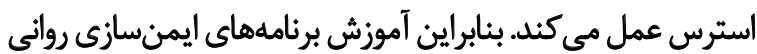
بر ويثگى هاى شخصيتى سهم: قابل توجهى دارد [ [ [1].

\section{Effectiveness}

8. Self-determination

9. Trust

10. Personal independence

11. Social accountability

12. Costa.

13. McCrae

14. Neuroticism

15. Extroversion

16. Openness

17. Agreeableness

18. Conscientiousness

1. Cerebral Palsy

2. Social competency

3. Personality traits

4. Meaningfulness sensation

5. Merit

6. Self-efficacy
كودكان با نيازهاى ويرُه، كودكانى هستند كه براي دستيابى به به بـان

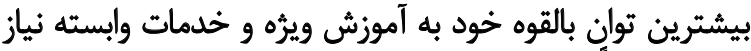

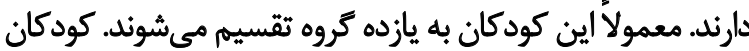

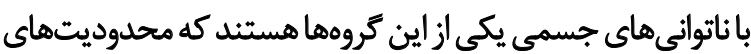

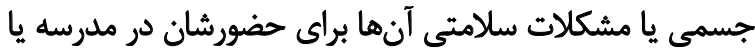

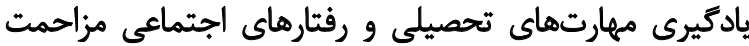

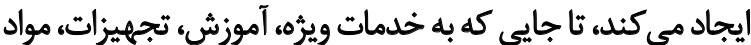

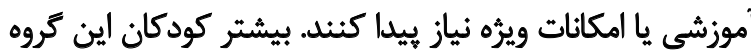

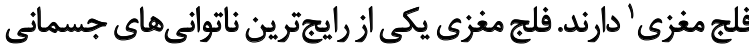

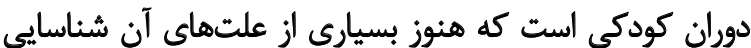

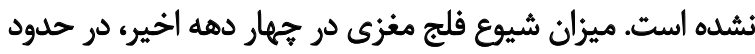
دو تا سه نفر در هر هزار تولد زئده كزارش شدئ شده است. اصطلاح فلج

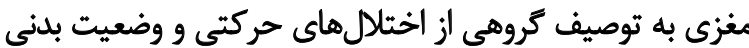

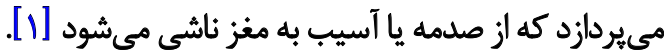
فلج مغزى نشانهاى بيجيدهاي دارد و انواع مختلف و درجات

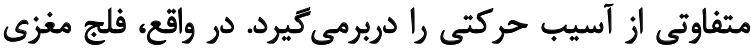

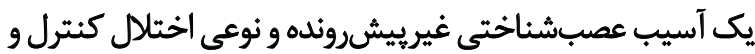

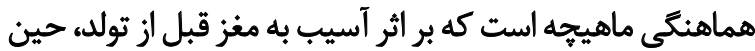

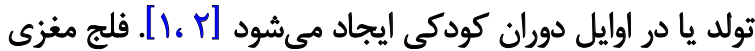

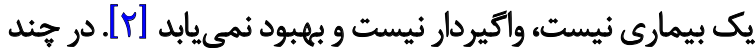

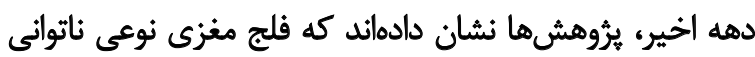

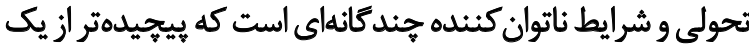

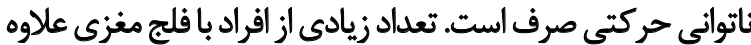

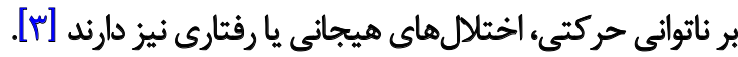
ناتوانىهاى افراد با فلج مغزى ابعاد جسمى و روانشناختى

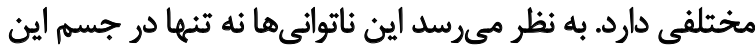

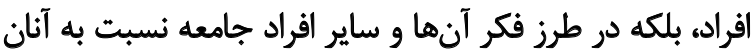

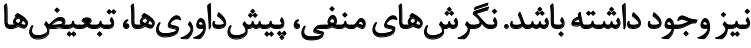

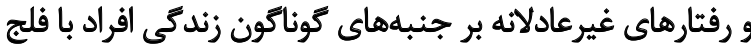

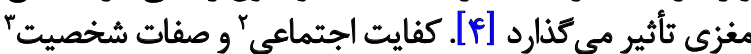

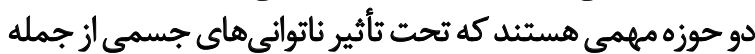

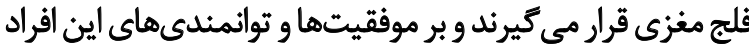

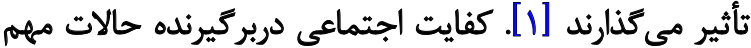

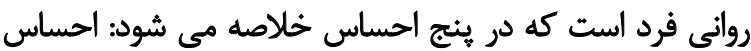

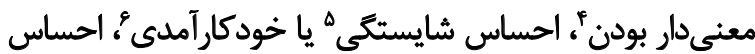




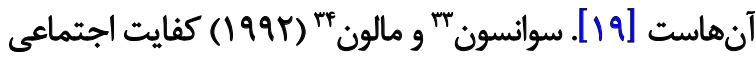
دانش آموزان داراى ناتوانى يادكيرى و عادى رابه كمك

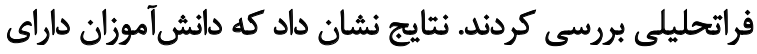

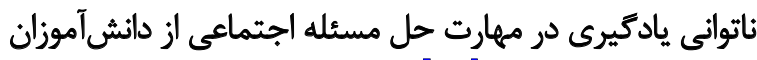

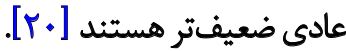

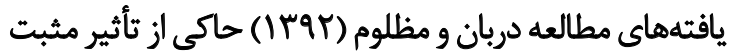

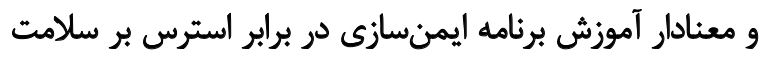

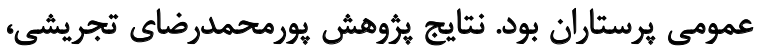

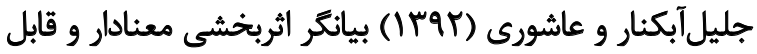

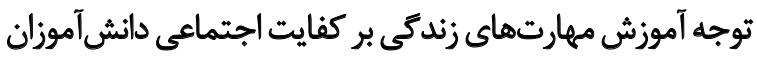

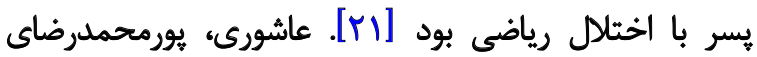

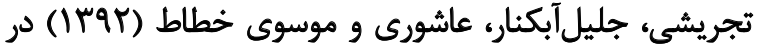

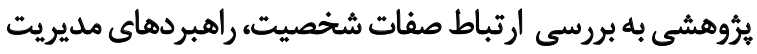

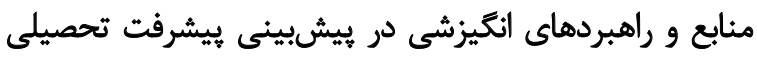

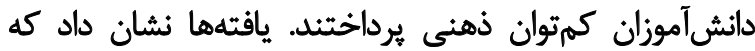

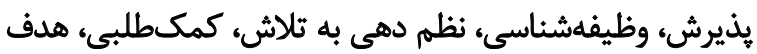

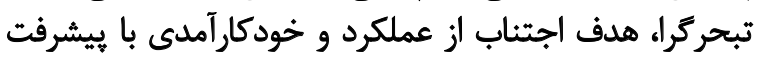

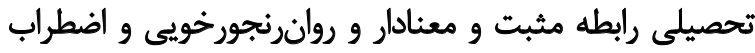

امتحان با بيشرفت تحصيلى رابطه منفى و معنادار دارند [N]

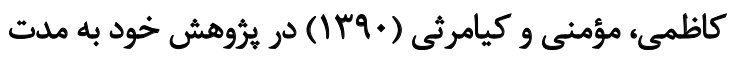

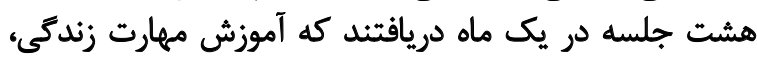

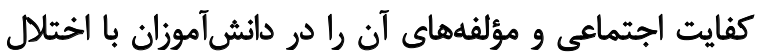

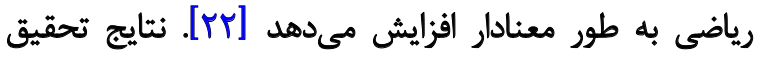

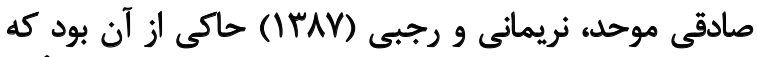

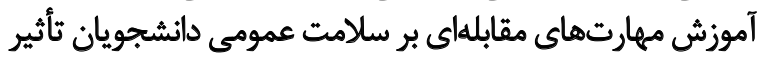

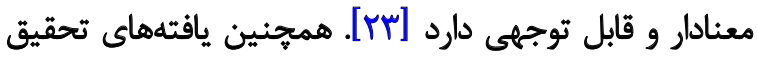

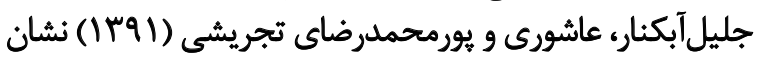

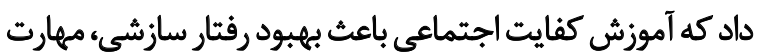

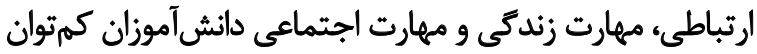

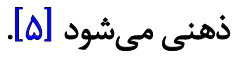

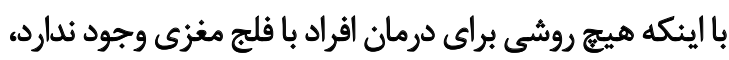

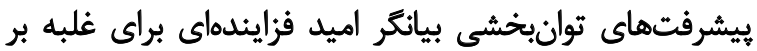

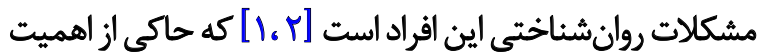

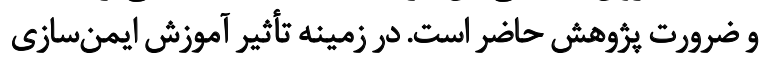

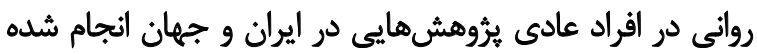

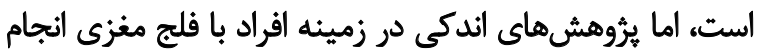

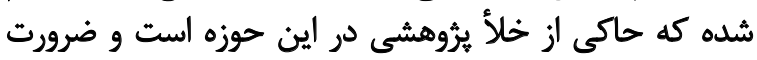

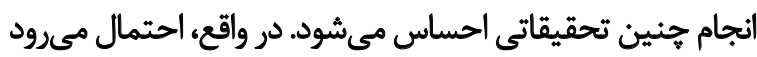

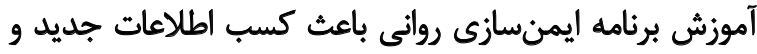

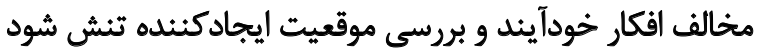

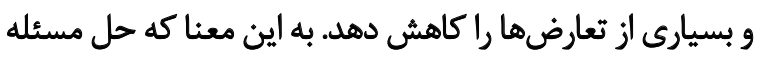

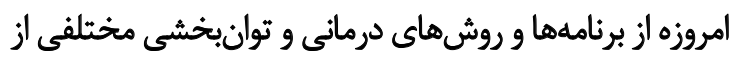

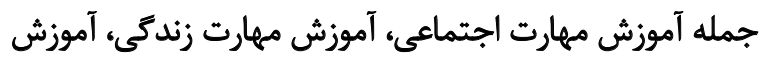

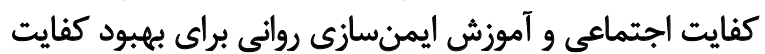

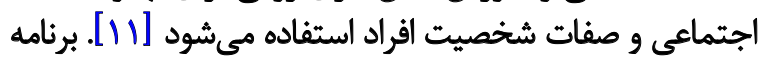

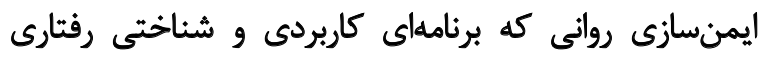

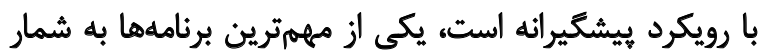

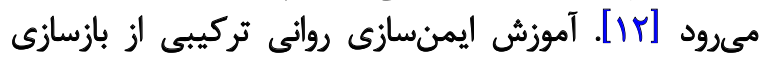

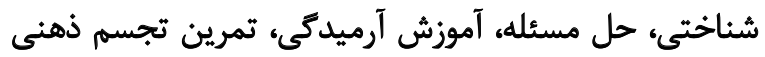

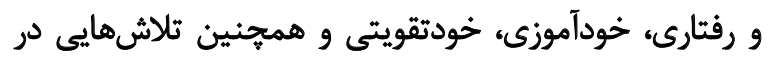

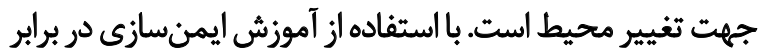

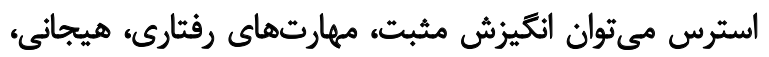

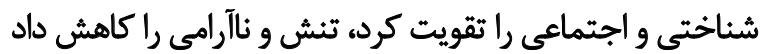

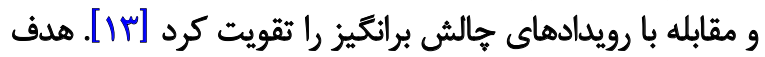

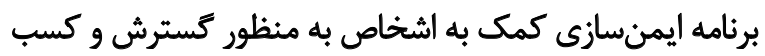

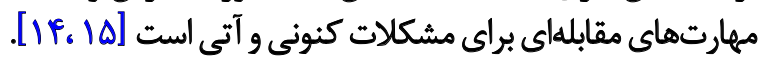

ايروهش هاى مختلفى در حوزه اثربخشى برنامه ايمنسازى روانى

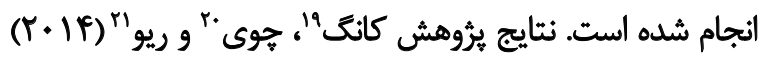

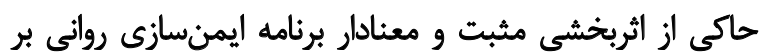

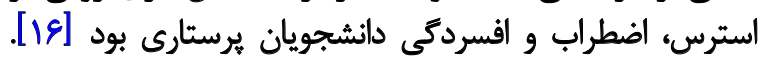

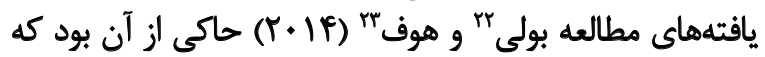

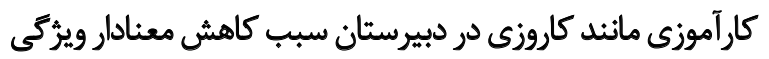

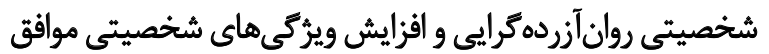

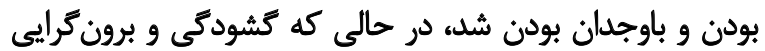

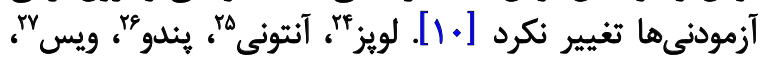

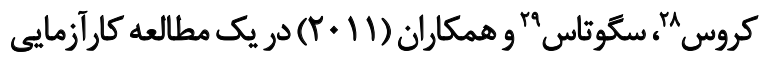

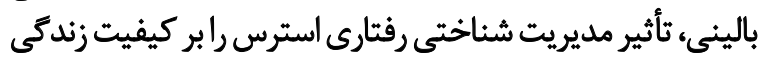

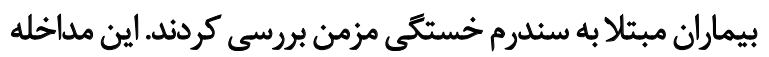

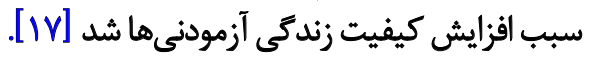

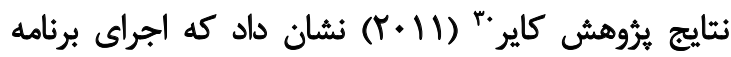

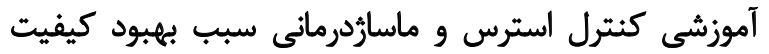

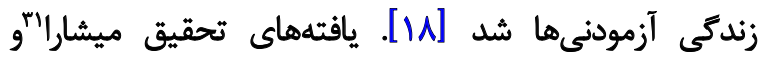

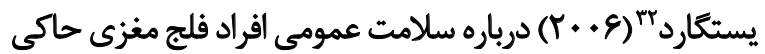

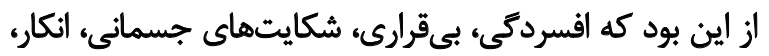

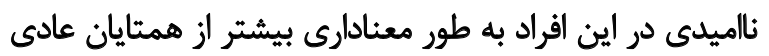
19. Kang
20. Choi
21. Ryu
22. Bolli
23. Hof
24. Lopez
25. Antoni
26. Penedo
27. Weiss
28. Cruess
29. Segotas
30. Keir
31. Mishara
32. Ystgaard 
براى جمعآورى اطلاعات از يرسشنامههاى زير استفاده شده

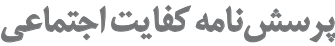

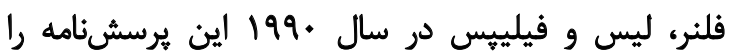

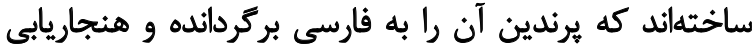

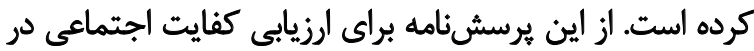

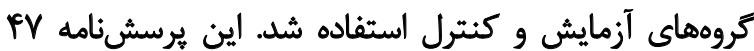

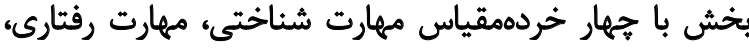

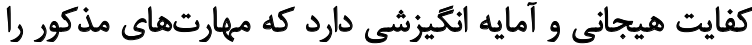

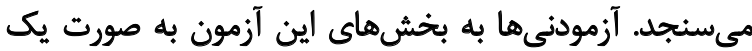

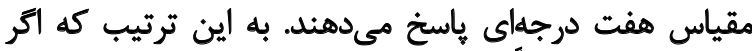

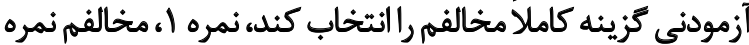

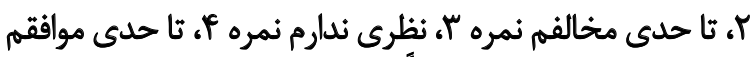

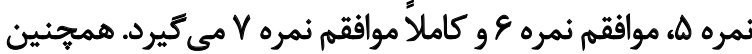

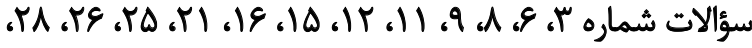

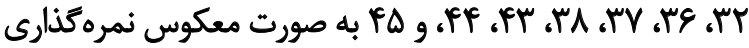

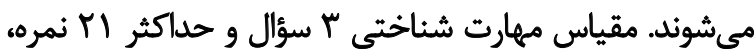

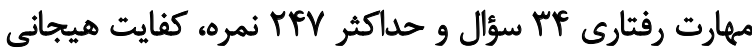

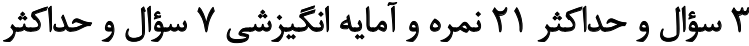

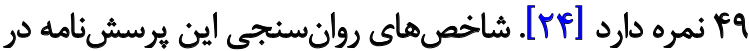

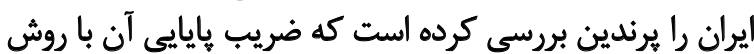

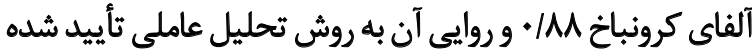

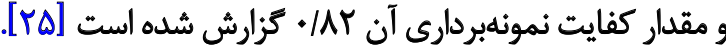

\section{يرسش نامه صفات شخصيت}

كاستا و مك كرى در سال بو 199 اين يرسشنامه را ساختهاند

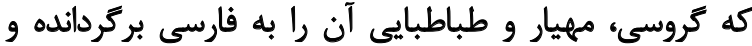

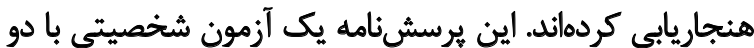

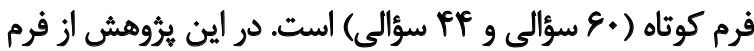

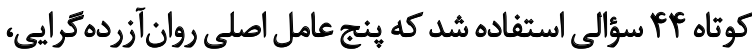

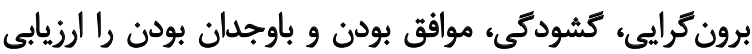

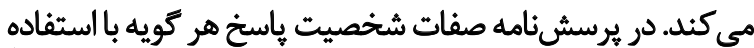

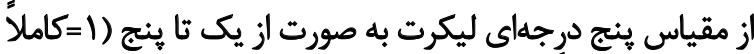

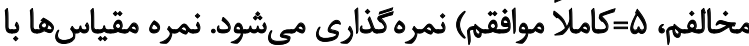

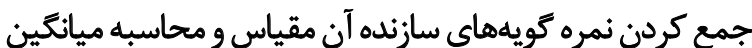

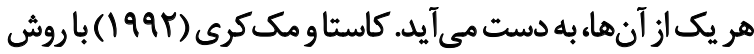

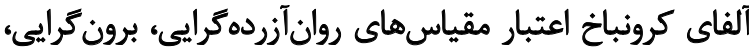

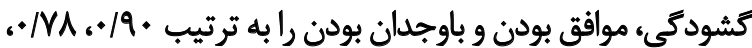

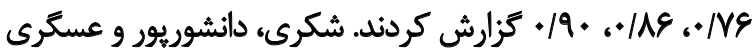
• • (ITAV)

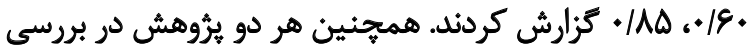

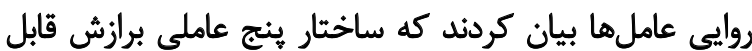

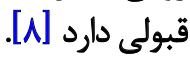

شناختى، هدف كزينيى مطلوب و انتخاب راهبردى كارآمد مي تواند

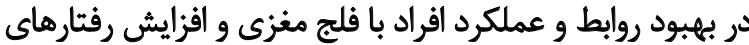

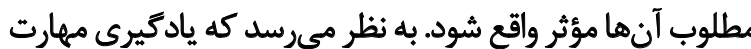

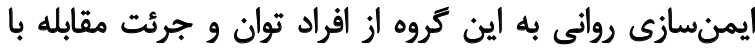

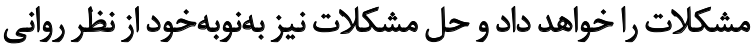
موجب مىشود تا احساس توانمندى و كفايت به فرد دست دهات ندات آنجه ضرورت و اهميت اين يُوهش را بيشازييش آشكار

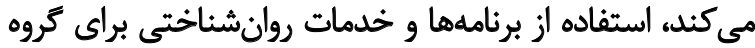

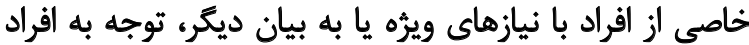

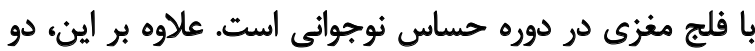

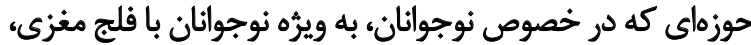

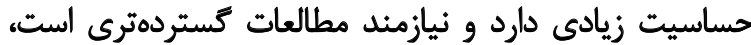

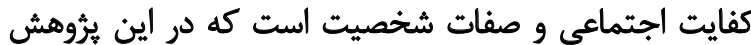

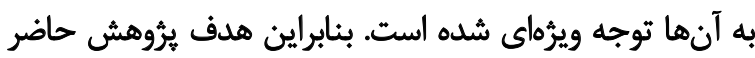

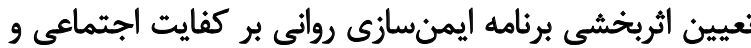
صفات شخصيت افراد با فلج مغزى است.

و

يثروهش حاضر از نوع تحقيقات شبهآزمايشى و طرح آن آن از

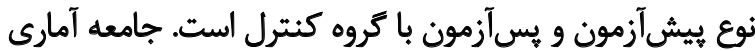

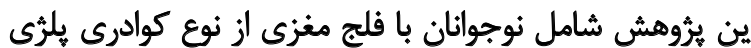

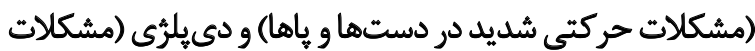

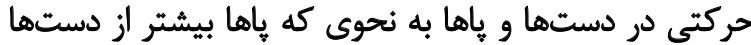

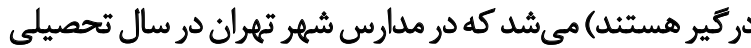

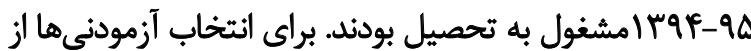

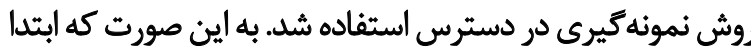

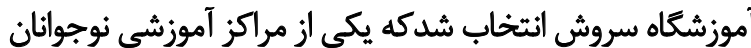

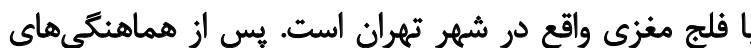

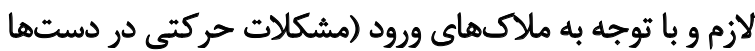

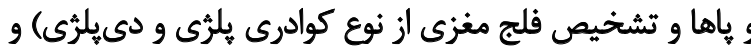

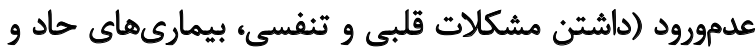

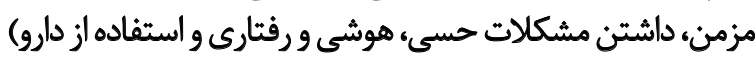

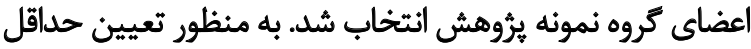

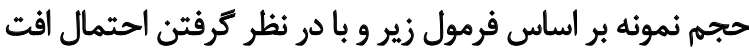

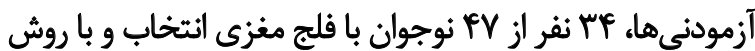

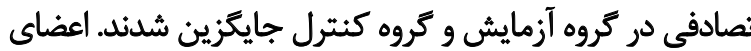

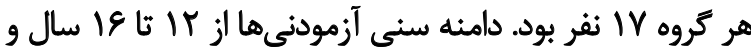

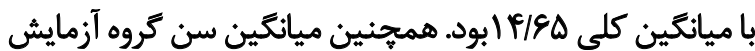

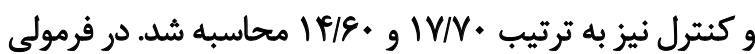

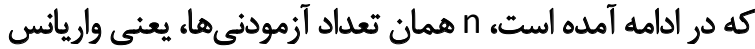

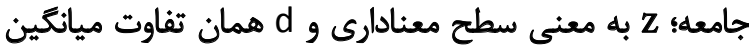

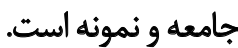
$n=\frac{\sigma^{2}\left(z_{1-\alpha / 2}\right)^{2}}{d^{2}}=(21 / 37)^{2} \times(1 / 96)^{2} /(11)^{2}=14 / 50$ 
جدول ا. محتواى جلسات آموزش برنامه ايمنسازى روانى در كروه آزمايش

\begin{tabular}{|c|c|c|}
\hline محتواى جلسات & 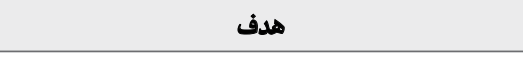 & 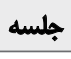 \\
\hline 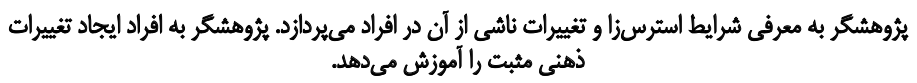 & مفهومسازى و توصيف استرس، ذعلاثم و ييامدهاى آن و & 1 \\
\hline يُؤوهشكر الكوهاى آرامشدهى در شرايط تنشزا را الرائه مىدهل. & أموزش آرامشدهى و تنشزدايى & $r$ \\
\hline يزووهشكر الفراد را به سمت شناسايى افكار و الحساسات مؤرثر در شرايط استرسزا هدايت مىكند. & 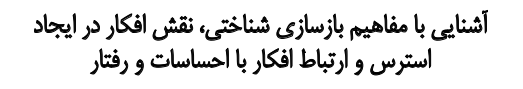 & $r$ \\
\hline يُورهشكر افراد را به شناسايى افكار منفى كه به طور ناأكاهانه به ذهن وارد مى شوده هدايت مى كند. & آشنايى با ويزكى هاى افكار خودآيند منفى و خطاهاى شناختى & r \\
\hline أموزش مهارتهاى مقابله با استرس و جكونكى مقابله با افكار منقى & مهارتهاى مقابله & $\Delta$ \\
\hline أموزش خودكويى هاى هدايتشلهه و نقش خودكويى هاى منفى در ايجاد استرس & خودمويعهاى هدايتشده & 8 \\
\hline يُؤششكر تكثيكهاى توجه بركردانى و تمركز فكر را آموزش مىدهل. & تمركز فكر و تكنيكهاى توجه بركردانى & $\checkmark$ \\
\hline أموزش هديريت زمان در هنكام بروز استرس و حل مسيله الجتماعى & مديريت زمان و حل مسثله اجتماعى & $\wedge$ \\
\hline أموزش مهارتهاى خودتنظيمى در شرايط استرس و نظارت بر خودكارآمدى براى مقابله با استرس & 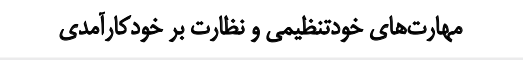 & १ \\
\hline تمرين مهارتهاي آموختهشده ولزوم به كاريري اين مهارتها در هنكام برخورد با هوقعيتهاى استرسزا & تمرين مهارتها & 1. \\
\hline
\end{tabular}

براى دو كروه آزمايش و كنترل با استفاده از روش آمارى تحليل

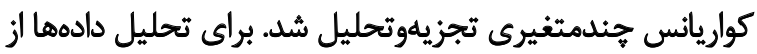
نسخه r ب نرمافزار آمارى SPSS استفاده شد.

Ladiól

شاخصهاى توصيفى مربوط به خردهمقياسهاي كفايت

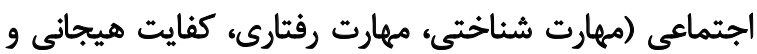

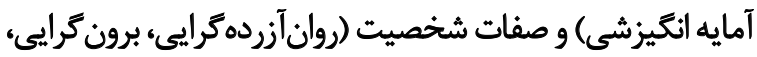

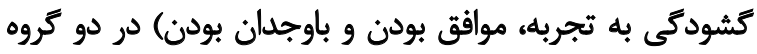

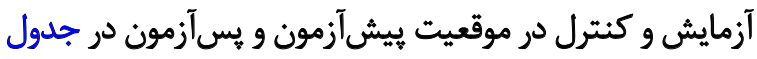
شماره Y ارائه شده است

نتايج جدول شماره ب نشان ميدهد ميانكين نمرات كفايت

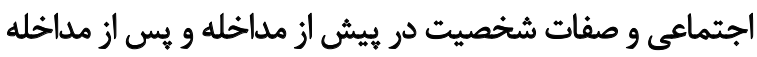

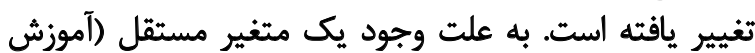

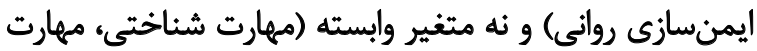

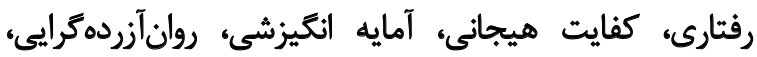

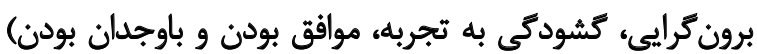

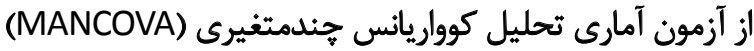

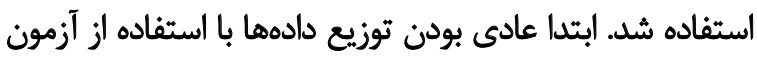

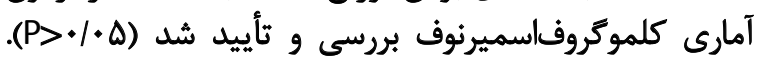

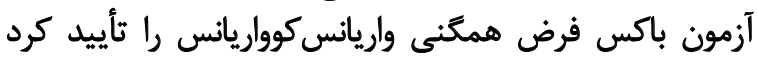

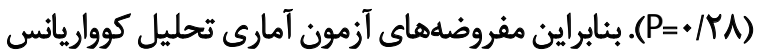

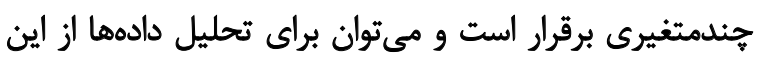

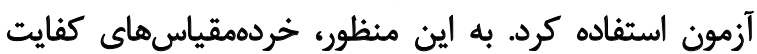
اجتماعى و ينج عامل صفات شخصيت نوجوانان با فلج مغزى درد

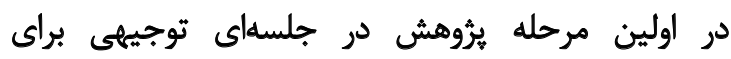

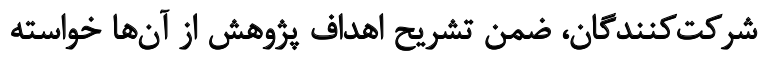

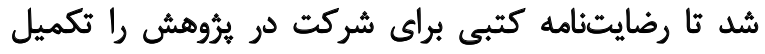

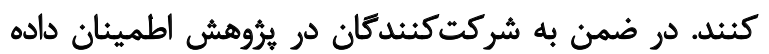

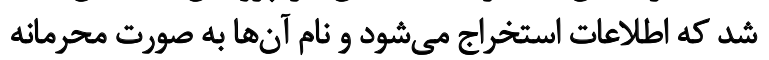

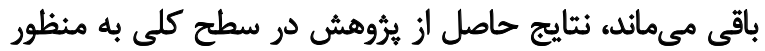

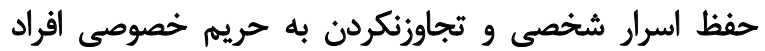

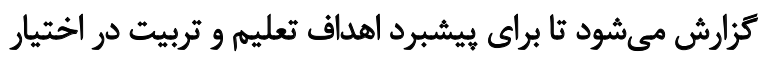

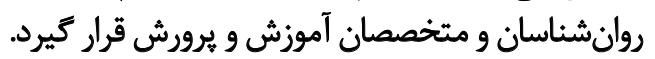

سيس يرسشنامه كفايت اجتماعى و صفات شخصيت به عنوان

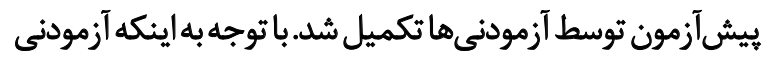

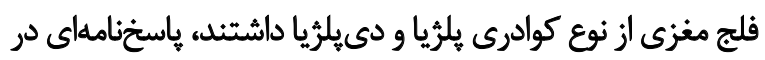

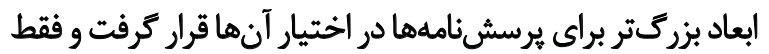

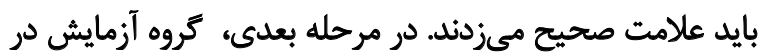

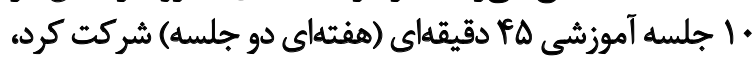

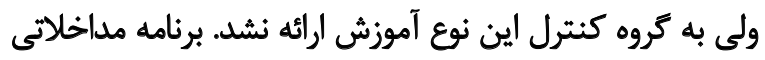

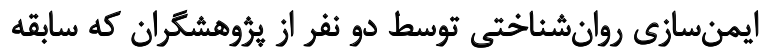

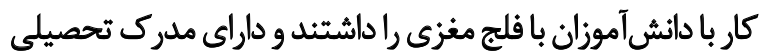

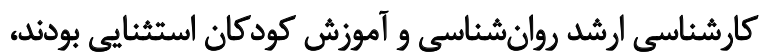

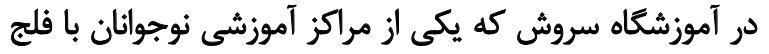

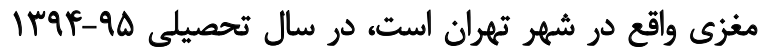

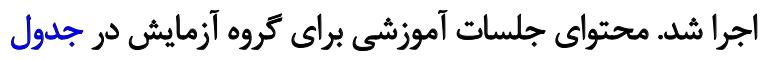

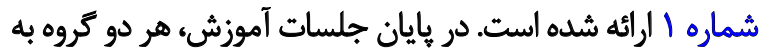

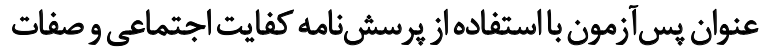

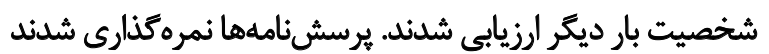

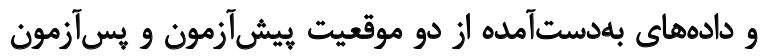


جدول Y. شاخص هاى توصيفى كفايت اجتماعى و ينج عامل صفات شخصيت

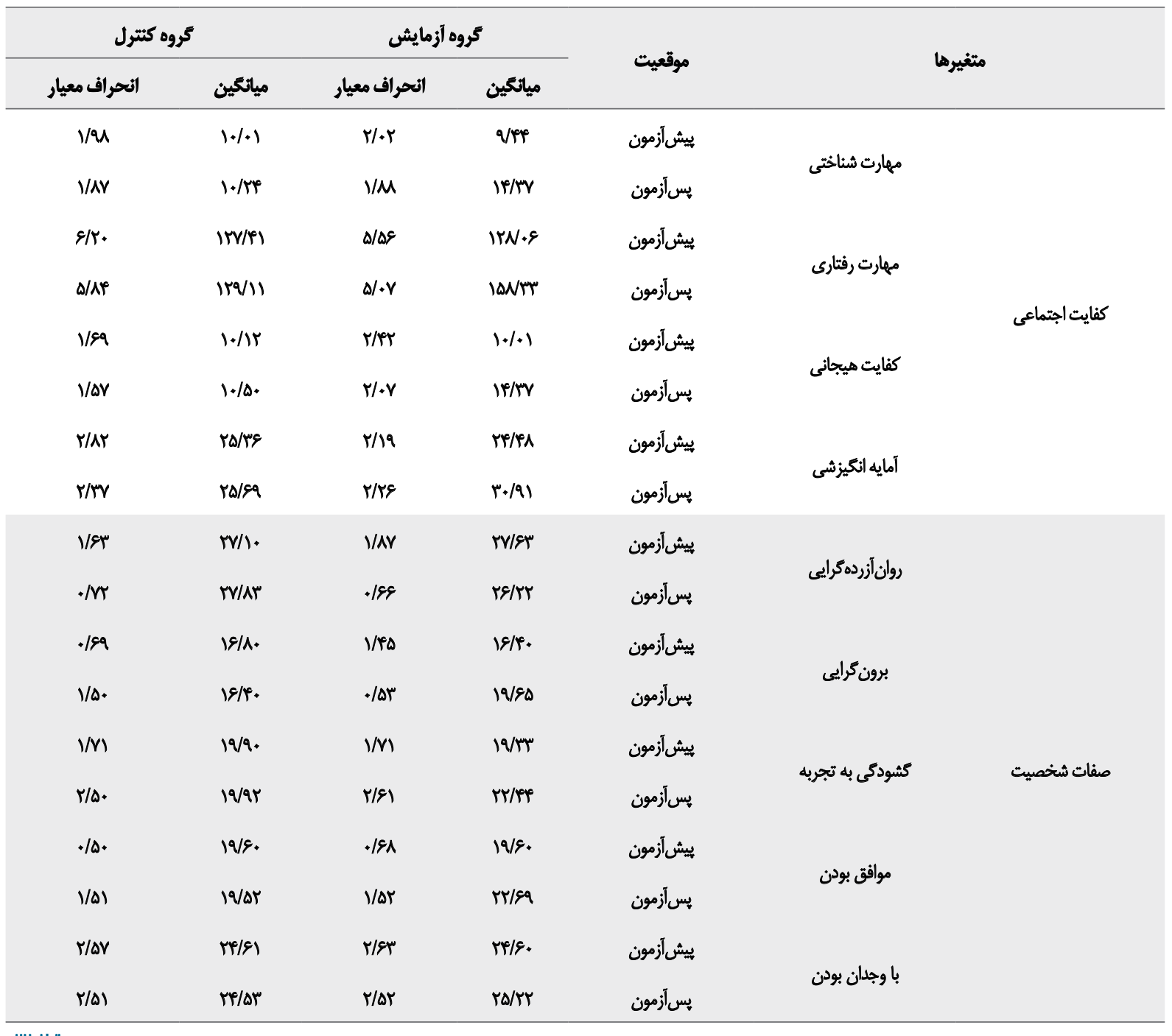

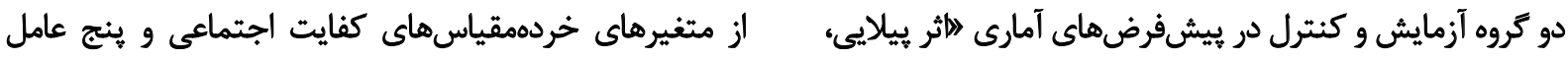

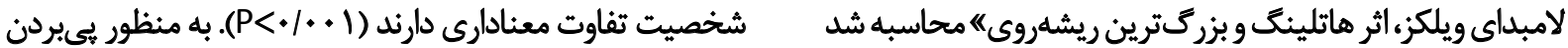

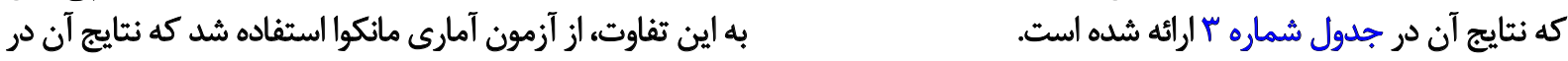

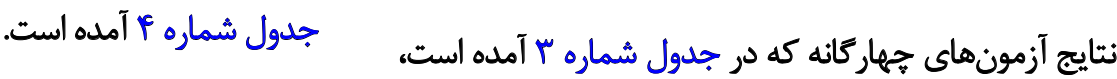

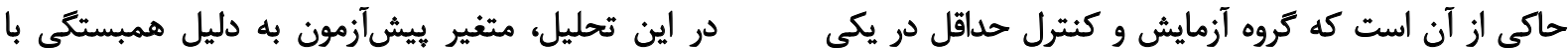
جدول ب. نتايج كلي تحليل كوواريانس جندمثغيرى براى كفايت اجتماعى و ينج عامل صفات شخصيت

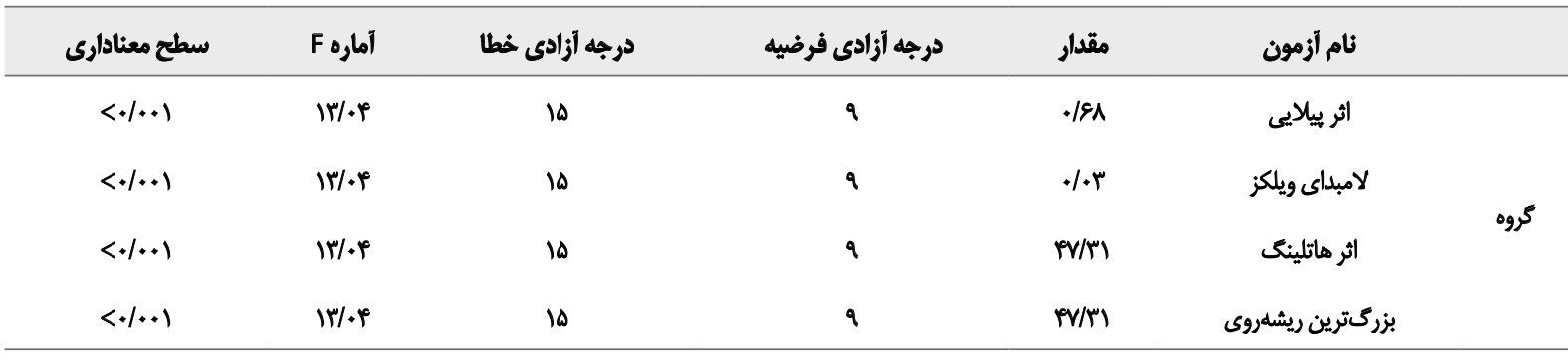


جدول f. نتايج تفكيكى تحليل كوواريانس جندمتغيرى براي متغيرهاي كفايت اجتماعى و بنج عامل شخصيت

\begin{tabular}{|c|c|c|c|c|c|c|c|}
\hline مجذور اتا & سطح معنادارى & أماره F F & مياتكين مجذورات & درجه أزادى & مجموع مجذورات & متغيرهاى وابسته & \\
\hline $.1 \Delta E$ & $+10+1$ & $V / . r$ & $W / \Delta E$ & 1 & $\mathrm{VA} / \Delta F$ & مهارت شناختى & \multirow{4}{*}{$y$} \\
\hline س & $+1 *+1$ & $19 / n$ & $1 \mathrm{~m} / \mathrm{Nr}$ & 1 & $I r \cdot / I V$ & مهارت رفتّارى & \\
\hline.$/ \Delta A$ & .101 & g/T & liem & 1 & $10 / 4$ & كفايت هيجانى & \\
\hline.$|8|$ & .10 .1 & $I E / M$ & 1.81 .4 & 1 & 1.81 .6 & آمايه انكيزشي & \\
\hline .109 & .10 .1 & $11 / \cdot 1$ & AV/RT & 1 & AV/AT & روان آز رده كرايى & \multirow{5}{*}{$\begin{array}{l}3 \\
3 \\
3 \\
3 \\
3\end{array}$} \\
\hline . $/ \Delta Y$ & $* .+1$ & $N T$. & re/gi & 1 & re/gi & برون كرايى & \\
\hline.$M 11$ & .1 .8 & I/TY & re/er & 1 & TE/TT & كشودكى به تنجربه & \\
\hline .101 & .1 .1 & $r / M q$ & $\Delta F / 9 F$ & 1 & $\Delta C / A Y$ & موافق بودن & \\
\hline سT/. & $.1 .+1$ & Ir/Aه & SV/VE & 1 & SV/VE & باوجلان بودن & \\
\hline
\end{tabular}

اجتماعى گروه آزمايش در مقايسه با كروه كنترل بود، اثربخشى ايخي

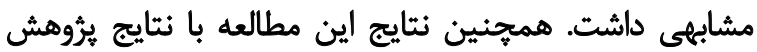

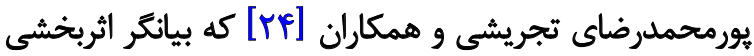

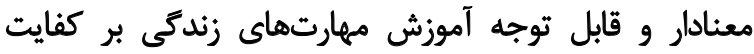

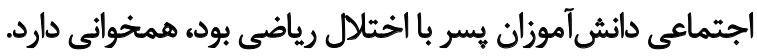

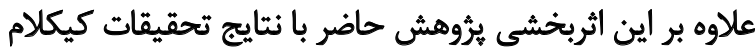

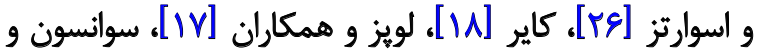

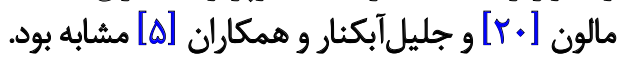

در تبيين اين يافته كه آموزش ايمنسازى روانى بر كفايت

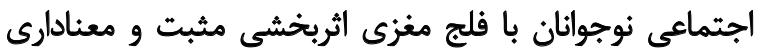

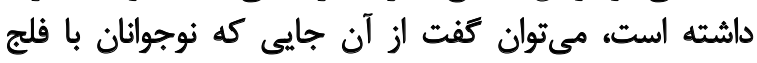

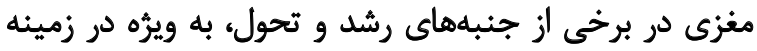

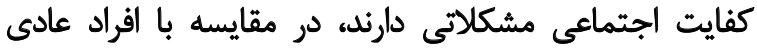

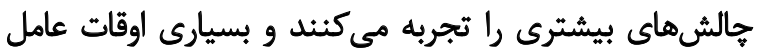

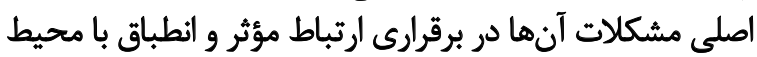

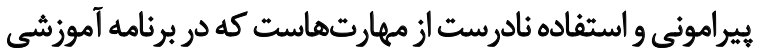

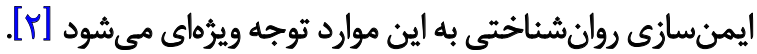

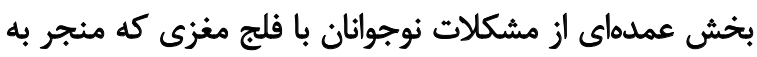

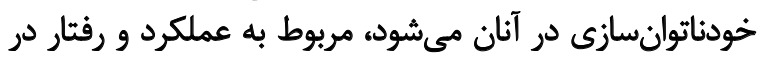

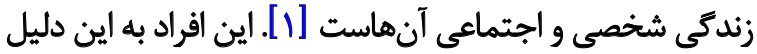

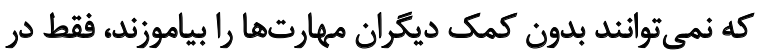

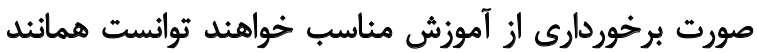

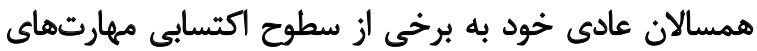

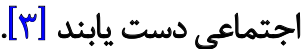

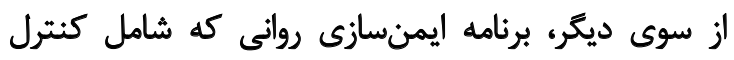

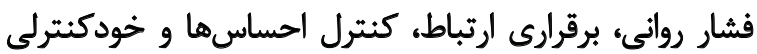
مىشود و از طرفى ساختار ارزشى، رشد اخلاقيى، و خودكارآمدى آلى
يسآزمون تعديل شده است. با توجه به نتايج جدول شماره

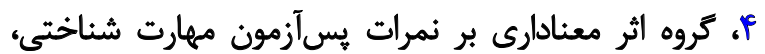

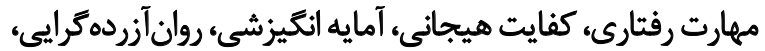

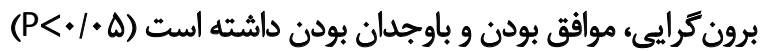

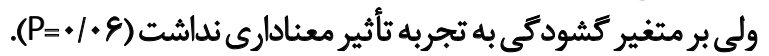

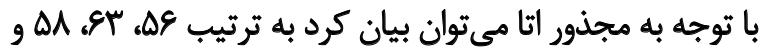

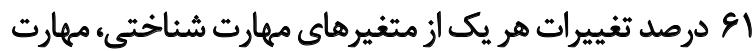

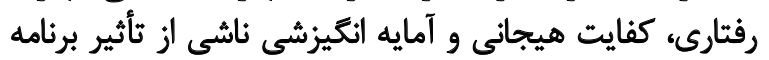

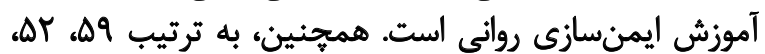

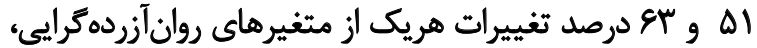

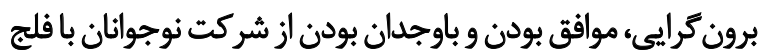

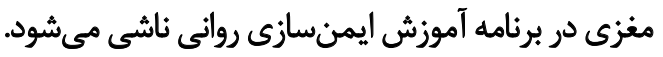

ث

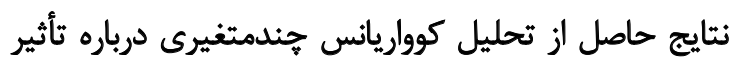

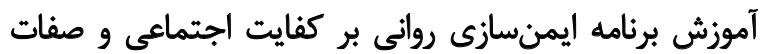

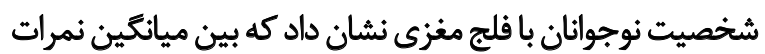

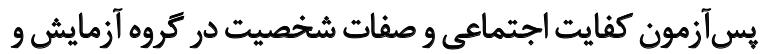

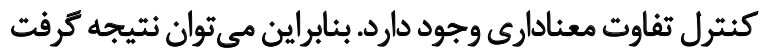

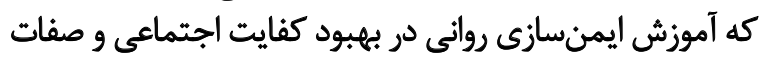
شخصيت آنها تأثير قابل توجهى داشئ درئه است كفايت

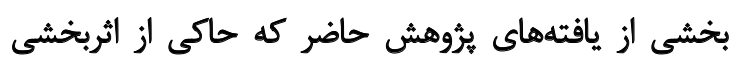

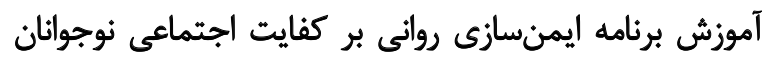

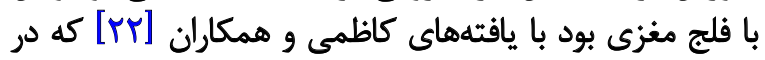

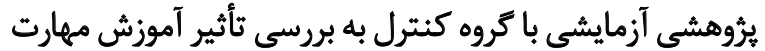

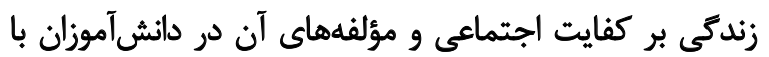

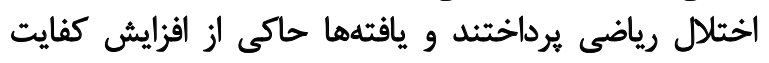


براى تبيين يافته ديكر يُوهش حاضر مبنى بر اينكه برنامه

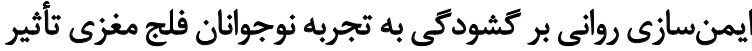

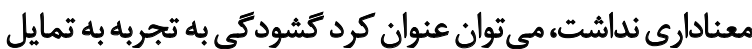

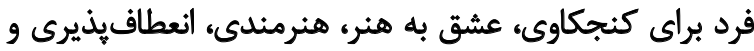

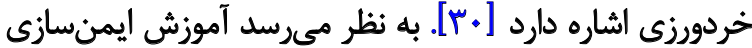

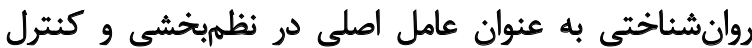

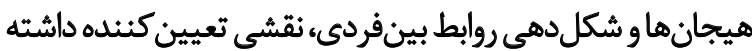

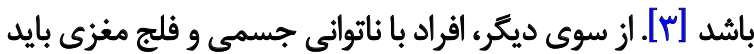

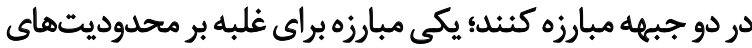

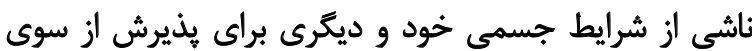

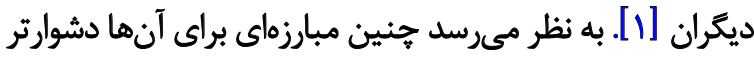

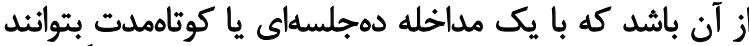
مبتكر، مستقل، خلاق و شجاع برآيند و اين ويرّكى نسبتاً باثبات باتيات

$$
\text { شخصيث آنان تغيير يابد. }
$$

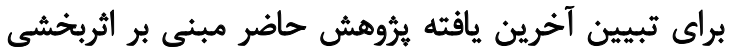

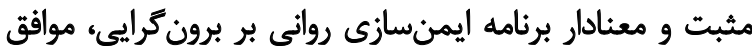

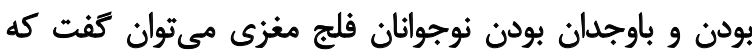

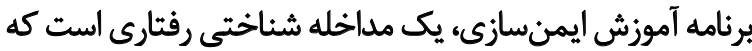

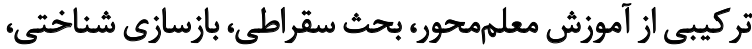

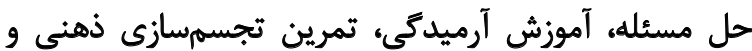

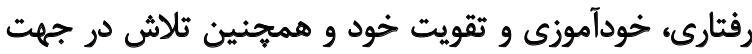

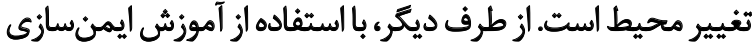

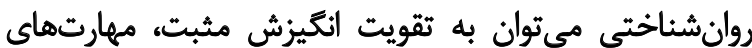

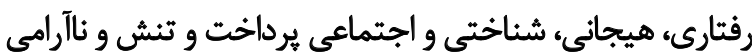

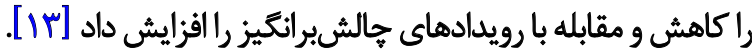

نوجوانان با فلج مغزى از طريق شركت در جلسات آموزشى

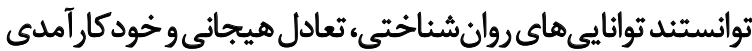

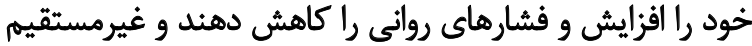

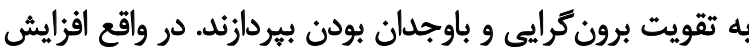

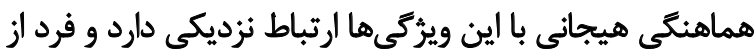

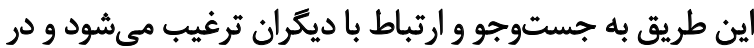

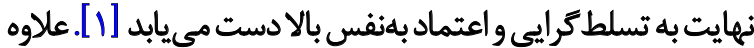

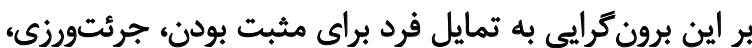

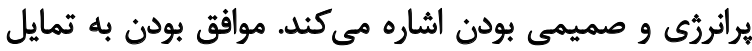

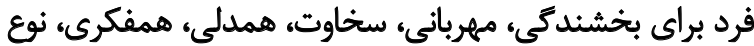

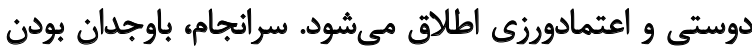

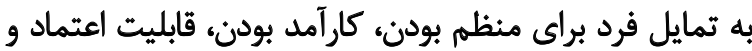

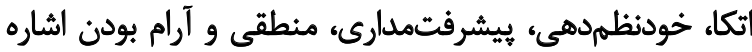

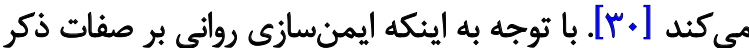

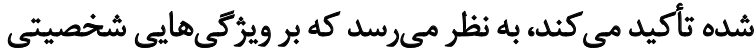

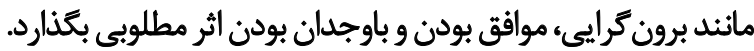
بنابراين، اكر براى افراد با فلج مغزى برنامه آموزشى مناسبى

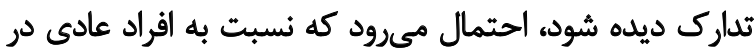

را دربرمى

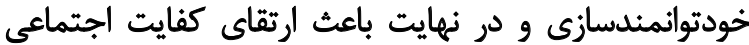

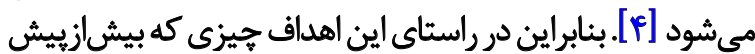

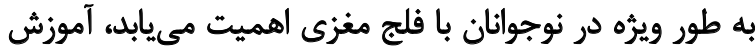

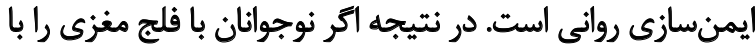

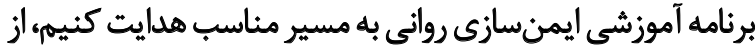

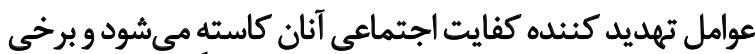

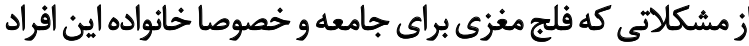

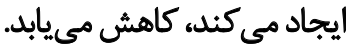

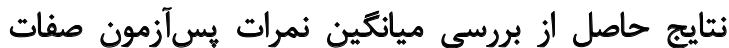

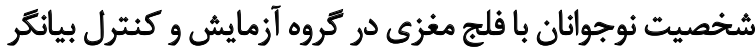

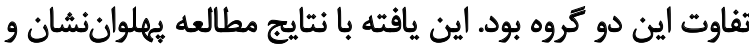

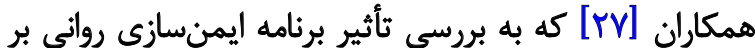

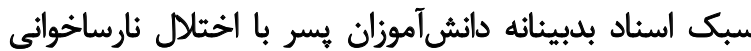

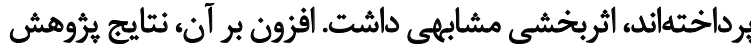

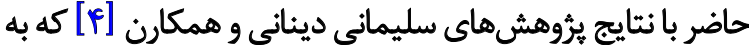

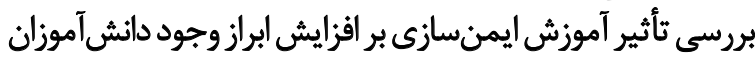

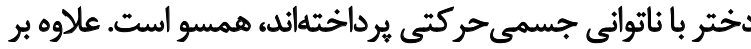

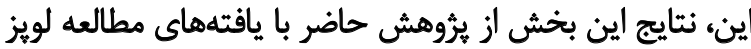

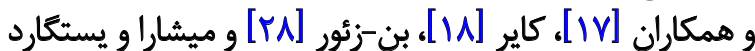

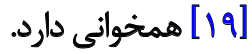

براى تبيين اين يافته كه برنامه ايمنسازى روانى سبب كاهش

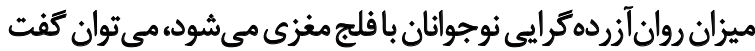

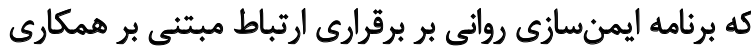

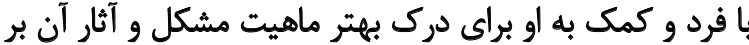

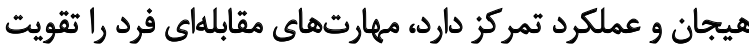

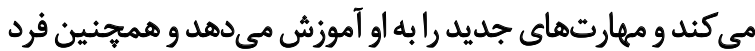

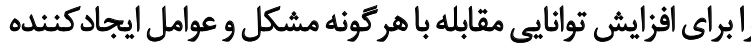

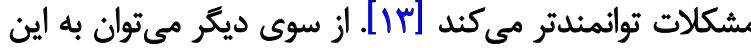

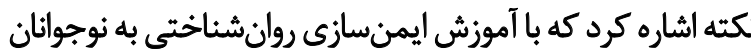

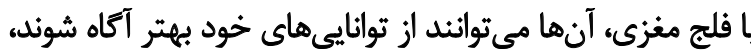

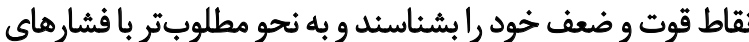

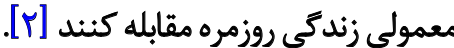
علاوه بر اين، افراد روانئزرده مضطرب، افسرده، تنيده،

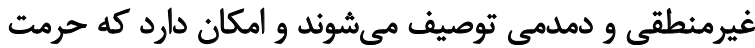

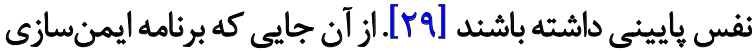

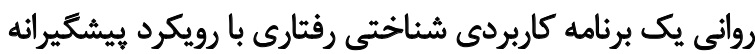

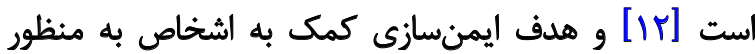

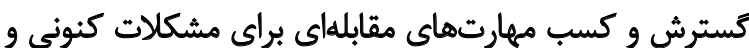

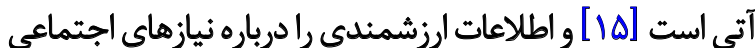

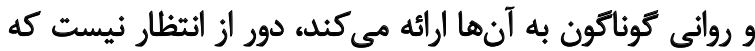

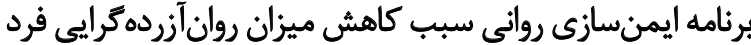

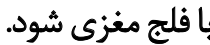


است ثا كفايت اجتماعى و صفات شخصيت مثبت نظير موفق

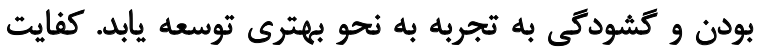

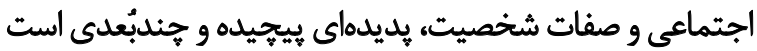

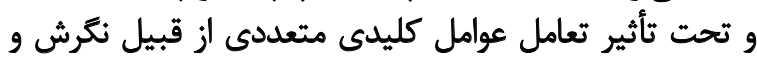

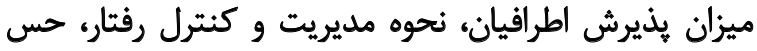

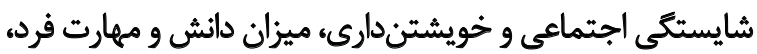

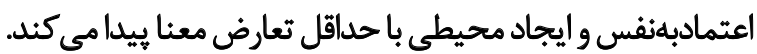

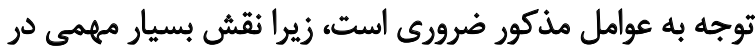

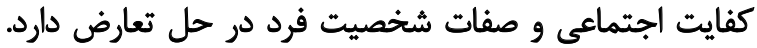

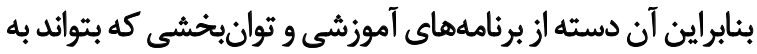

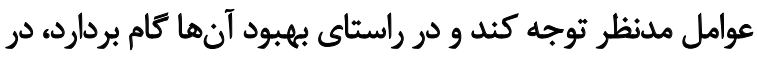

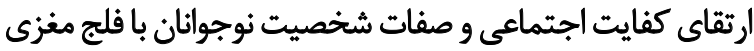

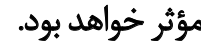

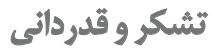

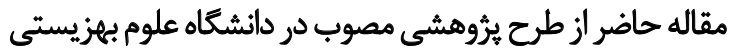
و توانبخشى كرفته شده كه با حمايت مالى كميته تحقيق مانيقات

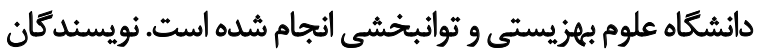

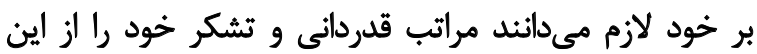

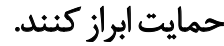

حوزه كفايت اجتماعى و برخى از صفات شخصيت بهبود بيشترى

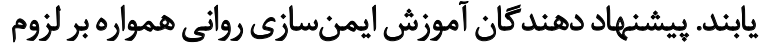

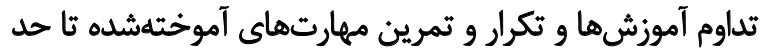

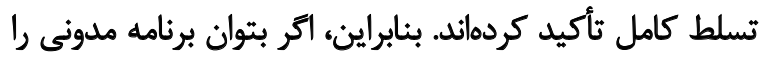

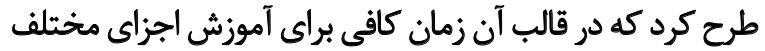

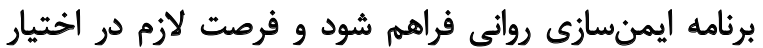

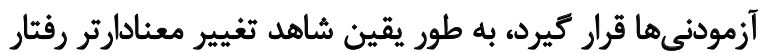

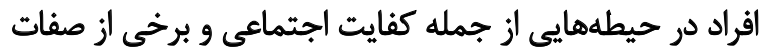
شخصيت خواهيم بود.

اين يروهش با محدوديتهايى مواجه بوده است كه عبارتند ازئ

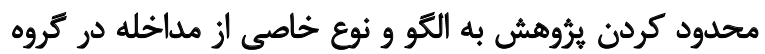

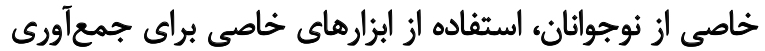

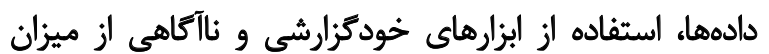

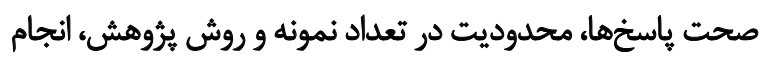

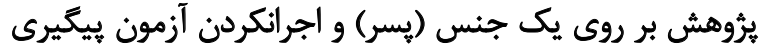

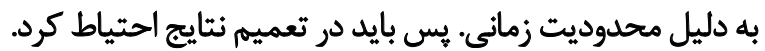

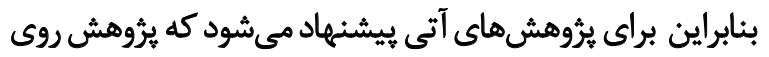

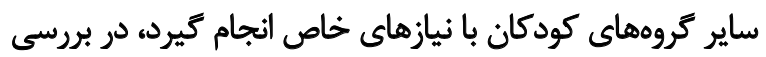

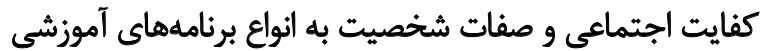

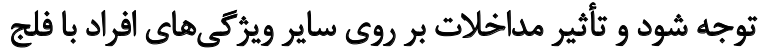

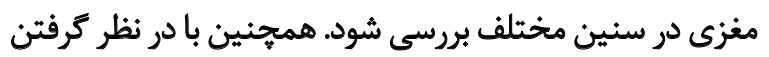

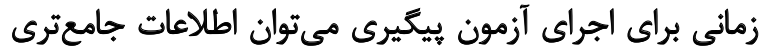

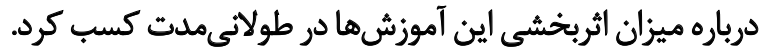

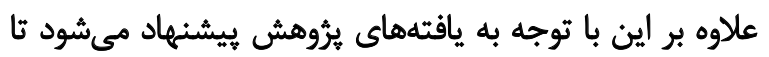

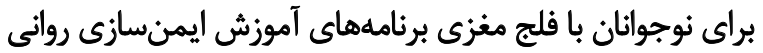

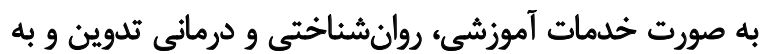
طور رسمى در مراكز خاص به آنهات آنها عرضه شود.

تثيجلمَيرى

ناتوانى جسمى حركتى، به ويرثه فلج مغزى به عنوان يك

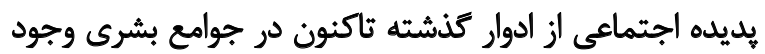

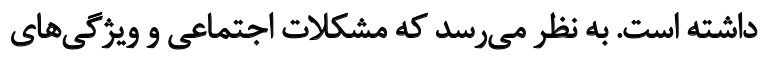

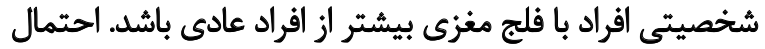

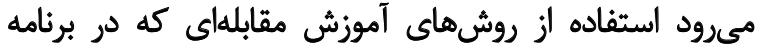

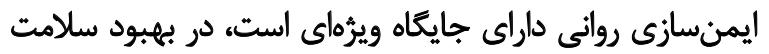

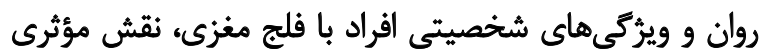

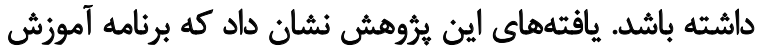

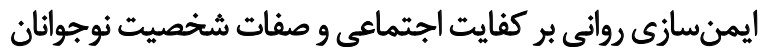

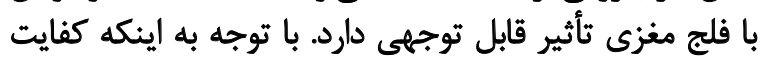

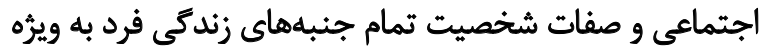

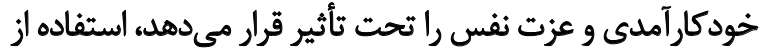

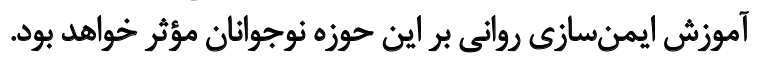
بنابراين به برنامه مدون آموزشى و توانبخشى ويرهاي نياز 


\section{References}

[1] Hallahan DP, Kauffman JM, Pullen PC. Exceptional learners: An introduction to special education. $13^{\text {th }}$ edition. New Jersey: Pearson Education; 2015.

[2] Ashoori M, Jalil-Abkenr SS. [Students with special needs and inclusive education (Persian)]. ${ }^{\text {st }}$ edition. Tehran: Roshd-e Farhang; 2016.

[3] Kirk S, Gallagher G, Coleman MR. Educating exceptional children. 14 ${ }^{\text {th }}$ edition. Massachusetts: Wadsworth Publishing; 2014.

[4] Soleimani Dinani M, Aliakbari Dehkordi M, Kako Joibari A, Moradi A. [The effectiveness of stress inoculation training on increased self-assertion of the physically-motor handicapped girl Students of high schools in Isfahan in 1389 (Persian)]. Psychology of Exceptional Individual. 2016; 1(4):73-90.

[5] Jalil-Abkenar SS, A'shouri M, Pourmohammadreza-Tajrishi M. [nvestigation of the effectiveness social competence instruction on the adaptation behavior in boy students with intellectual disability (Persian)]. Archives of Rehabilitation. 2013; 13(5):104-113.

[6] Felner RD, Lease AM, Philips RC. Social competence and the language of adequacy as a subject matter for psychology: A quadripartite travel framework. In: Gullotta TP, Adams GR, Montemayor R, editors. Developing Social Competence in Adolescence: Advances in Adolescent Development; Newbury Park: Sage; 1990.

[7] Rabinke M, Datillo F. Cognetive therapy in the children and teenagers [R. Alagheband. Persian trans]. $3^{\text {th }}$ edition. Tehran: Bogh'e; 2000.

[8] Ashori M, Pourmohammad Rezaei Tajrishi M, Jalil-Abkenar SS, Ashoori J, Moosavy Khatat M. [The investigation of relationship personality traits, resources management strategies and moti-vational strategies in predicting academic achievement on the students with intellectual disability (Persian)]. Middle Eastern Journal of Disability Studies. 2011; 1(1):1-14.

[9] Rufer M, Albrecht R, Schmidt O, Zaum J, Schnyder U, Hand I, et al. Changes in quality of life following cognitive-behavioral group therapy for panic disorder. European Psychiatry. 2010; 25(1):814. doi: 10.1016/j.eurpsy.2009.05.003

[10] Bolli TH, Hof H. The impact of apprenticeship training on personality traits: An instrumental variable approach. KOF Working Papers. Zurich: KOF Swiss Economic Institute; 2014.

[11] Noftle EE, Robins RW. Personality predictors of academic outcomes: Big five correlates of GPA and SAT scores. Journal of Personality and Social Psychology. 2007; 93(1):116-30. doi: 10.1037/0022-3514.93.1.116

[12] Sheehy R, Horan JJ. Effects of stress inoculation training for $1^{\text {st }}$ year law students. International Journal of Stress Management. 2004; 11(1):41-55. doi: 10.1037/1072-5245.11.1.41

[13] Meichenbam D. Stress inoculatin training: A preventative and treatment approach. $3^{\text {rd }}$ edition. Philadelphia: Guilford Press; 2007.

[14] Ashoori M, Jalil Abkenar SS, Pourmohammadrezaye Tajrishi M. [nvestigation of the efficacy of emotional intelligence training on the self-esteem in boy students suffering from hearing loss (Persian)]. Archives of Rehabilitation. 2014; 15(1):3-12.

[15] Kawaharada M, Yoshioka E, Saijo Y, Fukui T, Ueno T, Kishi $\mathrm{R}$. The effects of a stress inoculation training program for civil servants in japan: a pilot study of a non-randomized controlled trial. Industrial Health. 2009; 47(2):173-82. doi: 10.2486/indhealth. 47.173

[16] Kang YS, Choi SY, Ryu E. The effectiveness of a stress coping program based on mindfulness meditation on the stress, anxiety, and depression experienced by nursing students in Korea. Nurse Education Today. 2009; 29(5):538-43. doi: 10.1016/j. nedt.2008.12.003

[17] Lopez C, Antoni M, Penedo F, Weiss D, Cruess S, Segotas MC, et al. A pilot study of cognitive behavioral stress management effects on stress, quality of life, and symptoms in persons with chronic fatigue syndrome. Journal of Psychosomatic Research. 2011; 70(4):328-34. doi: 10.1016/j.jpsychores.2010.11.010

[18] Keir ST. Effect of massage therapy on stress levels and quality of life in brain tumor patients-observations from a pilot study. Supportive Care in Cancer. 2010; 19(5):711-5. doi: 10.1007/s00520010-1032-5

[19] Mishara BL, Ystgaard M. Effectiveness of a mental health promotion program to improve coping skills in young children: Zippo's Friends. Early Childhood Research Quarterly. 2006; 21(1):110-23. doi: 10.1016/j.ecresq.2006.01.002

[20] Swanson HL, Malone S. Social skills and learning disabilities: A meta-analysis of the literature. School Psychology Review. 1992; 21(3):427-443.

[21] Mazlom SR, Darban F, Vaghei S, Modarres gharavi M, Kashani Lotfabadi M, Shad M. [The effect of Stress Inoculation Program (SIP) on nurses' perceived stress in psychiatric wards (Persian)] Evidence Based Care Journal. 2012; 2(1):35-44. doi: 10.22038/ EBCJ.2012.388

[22] Kazemi R, Momeni S, Kiamarsi A. [The effectiveness of life skills training on the social competency of students with dyscalculia (Persian)]. Journal of Learning Disabilities. 2011; 1(1):94-108.

[23] Sadeghi movahhed F, Narimani M, Rajabi S. [The effect of teaching coping skills in students' mental health (Persian)]. Journal of Ardabil University of Medical Sciences. 2008; 8(3):261-269.

[24] Pourmohamadreza Tajrishi M, Jalil Abkenar SS, Ashoori M. [The effectiveness of life skills training on the social self-competency in boy students with dyscalculia (Persian)]. Journal of Clinical Psychology. 2013; 5(2):1-11.

[25] Parandin SH. [Construct social self-competency questionnaire and its normalization of teenagers in Tehran city (Persian)] [MSc. thesis]. Tehran: Allameh Tabataba'i University; 2006.

[26] Keikelame MJ, Swartz L. Lost opportunities to improve health literacy: Observations in a chronic illness clinic providing care for patients with epilepsy in Cape Town South Africa. Epilepsy \& Behavior. 2013; 26(1):36-41. doi: 10.1016/j.yebeh.2012.10.015

[27] Pahlavan-Neshan S, Pourmohamadreza-Tajrishi M, Sajedi F Shokri O. [The effect of psychological immunization program on pessimistic attribution style of boy students with dyslexia (Persian)]. Archives of Rehabilitation. 2014; 15(3):52-62. 
[28] Ben-Zur H. Coping styles and affect. International Journal of Stress Management.2009; 16(2):87-101. doi: 10.1037/a0015731

[29] Hayes N, Joseph S. Big 5 correlates of three measures of subjective well-being. Personality and Individual Differences. 2003; 34(4):723-7. doi: 10.1016/s0191-8869(02)00057-0

[30] Costa P, Terracciano A, McCrae RR. Gender differences in personality traits across cultures: Robust and surprising findings. Journal of Personality and Social Psychology. 2001; 81(2):322-31. doi: 10.1037/0022-3514.81.2.322 